\title{
INTERNAL ENVIRONMENTAL FACTORS AND THE LEVEL OF ADOPTION OF HRIS
}

\author{
A Chamaru De Alwis, Berislav Andrlic \& Marko Sostar
}
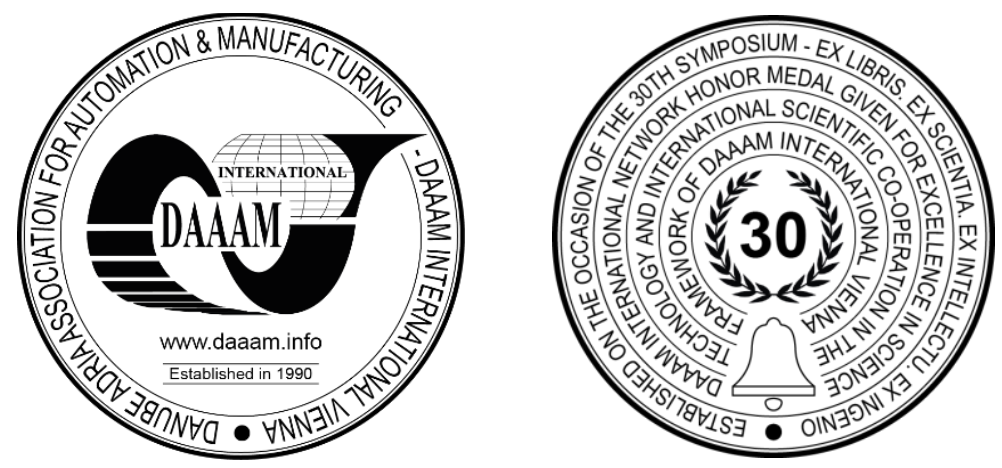

This Publication has to be referred as: De Alwis, A[dambarage] C[hamaru]; Andrlic, B[erislav] \& Sostar, M[arko] (2019). Internal Environmental Factors and the Level of Adoption of HRIS, Proceedings of the 30th DAAAM International Symposium, pp.1196-1201, B. Katalinic (Ed.), Published by DAAAM International, ISBN 978-3-90273422-8, ISSN 1726-9679, Vienna, Austria

DOI: $10.2507 / 30$ th.daaam.proceedings.168

\begin{abstract}
Current study attempts to examine the relationship between internal environmental factors and the level of adoption HRIS. An integrated conceptual framework was integrated ideas and elements from the diffusion of innovation theory and technology organization environment model. The study was quantitative and cross-sectional survey design was followed. Population was Sri Lankan organization and Convenience sampling technique were applied to select the sample, and the sample consisted of 93 organizations located in Sri Lanka. It was found that internal environmental factors significantly related to the level of adoption of HRIS applications, which in turn has an impact on the level of adoption of HRIS application.
\end{abstract}

Keywords: Human Resource Information System; Adoption of HRIS Application; Internal Environmental Factors

\section{Background of the study}

According to [10] "Human Resources (HR) and Information Technology (IT) are the two elements that many organizations are learning to use as strategic weapons to compete". However, to get benefit from those two, those should be amalgamated in a perfect manner [16] [17]. For that purpose, human resource information system was emerged [12]. HRIS can be defined as "one which is used to acquire, store, manipulate, analyze, retrieve, and distribute information about an organization's human resource" [20]. The purpose of HRIS is initiating and implementing of information system in order to perform HR tasks [2].

Currently, HRIS covers all human resource management function such as personal information, recruitment, training, career management, performance management, compensation and benefits administration, labor contracts and employee relationship management and it is considered to be a process of information collection, storage, analysis, and reporting. HRIS is a valid method to obtain relevant information timely for decision-making. So most of the organizations are ready to adopt changes if they feel to have competitive advantage.

Even though some organizations are ready to change many organizations resist this new technology implementation, including HRIS. Past researchers have recognized no of resistance come from and divided those into two main clusters as internal environmental factors and external environment factors. According to [2] government, policies and support 
[20]: [2], social influences [2], and [15] and industry and market structure [7] are the main influential external factors. [23] revealed that departmental relative advantage, compatibility, top management support, organization size, and HRIS expertise are positively related to the adoption of HRIS. [2] recognized five internal factors. Those are: management expectations, organizational dynamic capabilities, organizational structure, management commitment, and corporate culture, CEO's socio-demographic characteristics and management expectations.

Since the last decade, the usage of HRIS has increased significantly [9], [5], [13]. However, E-HRM adoption in developing countries indicates a relatively slow rate. This slow adoption rate is a critical issue as organizations in developing countries are now engaging more in international business where adoption of e-HRM is required to compete in international context [20] as cited by [8].

Authors [13] [3] conducted a study using scale developed by [2] in Sri Lankan Context. However, according to [13] just organizational culture and management commitment have a significant positive relationship with HRIS adoption. However, in 2018 [13] found a significant positive relationship between all factors and HRIS adoption with a larger sample (However, both have done this it for the manufacturing sector the Sri Lankan sector). In 2016, [17] conducted a study for the service sector and confirm a significant positive relationship. However, there is no study to measure the entire country. The fore, here our expectation was to conduct a study for the entire country.

As mentioned above the majority of researches were conducted among firms in developed countries. But due to the contextual changes among developed and developing countries results of these studies are unlikely to generalize within developing countries. Thus it can consider as a lacking area in developing countries.

This study examines the relationship between internal environmental factors and the level of adoption of HRIS application in Sri Lankan organizations. Thus, the research problem of this study can be stated as:

Do internal environmental factors affect to the level of adoption of HRIS allocations in Sri Lankan organizations?

\section{The Significance of the Study}

This scientific study will provide an understanding of HRIS adoption behavior of Sri Lankan organizations by testing the phenomenon in a new environment. Firm-level adoption behavior of HRIS has been investigated in developed countries but very little researches have been conducted in developing countries, particularly within Sri Lanka. Therefore, this study contributes to the existing body of knowledge by enhancing current understanding of the organizational adoption of HRIS. The technological adoption field assists IS researchers with a new avenue for studying IT adoption and implementation.

The present study has important implications for studies aimed at understand HRIS implementation in developing countries. However, explanations of findings will indicate the importance of contextual factors within an organization and its environment. By highlighting the significance of several contextual factors, this study also hopes to expand the focus of HRIS. This study provides some insights into the implementation of HRIS by Sri Lankan companies, which should help HR practitioners, acquire a better understanding of the current HRIS implementation status and applications. The empirical research conducted in HRIS's adoption in Sri Lankan context is limited in quantity, this will add uniqueness for this study which may become the basic foundation for other researches in this atmosphere.

The importance of this study derived from the importance of the level of adoption of HRIS application, it is as the backbone of every organization, thus the level of adoption of the resources will determined the success or frailer of any organization. The analysis of the internal environmental factors of HRIS adoption and its implementation in Sri Lanka will provide valuable insights for the companies and organizations taking part in the study. The results made it possible for the participating companies and organizations to benchmark themselves against other global and local organizations. Additionally, the practical relevance of this study will justify through helping HR managers and the top management to understand the interplay of factors that influence the adoption level of HRIS in the organizational context, which may ultimately help with influencing the decision-making processes and to gain competitive advantages and to survive within the current global economy and marketing.

Additionally, the study could support the HR managers in two ways: it assists HR managers in Sri Lankan to adopt HRIS applications confidently; by evaluating the potential advantages and disadvantages of investment in IT (both hardware and software) applications before deciding to adopt them and it helps HR divisions to perform strategically within the current businesses.

Also, this study is going to undertake in Sri Lankan context, the organization's decision-makers can identify the exact major internal factors which affect the level of adoption of HRIS application and they can focus on those factors when making investments to initiate and implement. 


\section{Methodology}

In this study the nature of the certain relationship between variables will be investigated through the hypothesis testing. Thus the research can be identified as explanatory or hypothesis testing in nature. Also, this was a field study which was conducted to understand whether there is a relationship between internal environmental factors and the level of adoption of HRIS. This can be identified as a cross-sectional study as data was collected within a particular period of time. The study setting of this research is non-contrived. Because this study examines the correlation between Internal environmental factors and the level of adoption of HRIS in Sri Lankan organizations in a natural working environment where events were normally occurring. This research study will be conducted according to the deductive research approach by survey technique. The researcher uses online and offline surveys to collect data. In addition to that, a standard questionnaire was used for the data collection.

As stated in the research objectives on the second chapter, the present study is attempt to assess the relationship between internal environmental factors and the level of adoption of HRIS application in Sri Lankan companies. Drawn from the literature on internal factors and the level of adoption of HRIS application, this study proposes the following conceptual framework.

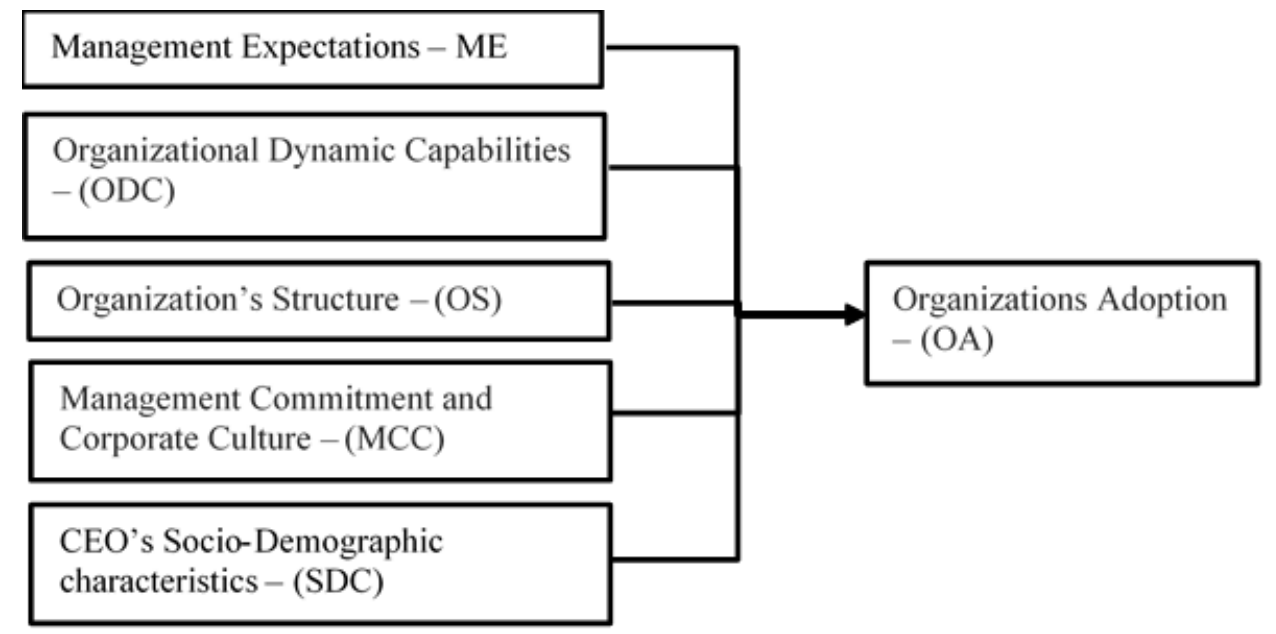

Figure: Conceptual framework of the study Source: [2]

\subsection{Operationalization of Variables}

Management Expectations (Perceived HRIS Characteristics)

In the adoption of innovation behavior, management expectations are proposed as "the managers' subjective evaluations of potential benefits of adoption of HRIS for their organizations, and is based upon their own experience or other firm's experience as well as their perception of the potential impact of the dynamic technology environment on their firms" [2]. and [1]. The dimensions of the variable are perceived relative advantage, complexity and computability.

Organizational Dynamic Capabilities :

The study used [23] definition on organizational dynamic capabilities is the firm's ability to integrate, build and reconfigure internal and external competencies to address rapidly changing environment [23]. Indicators of the variable are the size and the employment stricture, business experience, organization resources, organizational resources, IT experience and capabilities.

Organization's Structure - (OS)

It is concern about the degree of centralization of the organization and it was expected to evaluate using formalization. specialization, and centralization.

Management Commitment

"Management commitment" is viewed as the extent of top management's support and willingness to adapt their organizational culture and management the process to meet the requirements of the adopting HRIS applications [2]. Indicators of the variable are top management willingness to support, intra-organizational communication, corporate culture

CEO's socio-demographic characteristics - (SDC) 
The researcher defines the concept as to what extent the collection of decision makers' demographic characteristics, social skills, and technological skills and leadership style commits to the adoption of IT innovation.

The Organization's Adoption and the Level of Implementing HRIS

The organizational adoption of HRIS can be identified as the process of initiating and implementing IS in order to perform HR tasks [2] and further he recognized two indicators separately to achieve the study's objectives: the adoption and the level of implementation of HRIS applications. Here we have used the same for this replication of the study in a different context.

\subsection{Hypotheses of the Study}

Based on the above conceptual framework the following hypotheses were advanced to be tested

(H1) - There is a significant relationship between internal environmental factors and the level of adoption of HRIS

(H1a) - There is a significant relationship between management expectation and level of adoption of HRIS application

(H1b) - There is a significant relationship between organizational dynamic capabilities and the level of adoption of HRIS application.

(H1c) - There is a significant relationship between organizational structure and the level of adoption of HRIS application. (H1d) - There is a significant relationship between management commitment and corporate culture and the level of implementation of HRIS

(H1e) - There is a significant relationship between CEO's socio-demographic characteristics and the level of adoption of HRIS application.

Sri Lankan organizations were taken as the population of this study and using random sampling 120 HR professionals were selected from different companies for this research. Questionnaire method was selected as the data collection method. Data was collected by using five points Likert scale closed-ended questions developed by author [1] .

The questionnaire was divided into three sections. The first section, item no 1 to 16 are background information. Section 2 was allocated to measure the level of HRIS application used and respondents were required to make a choice from the HRIS implementation elements listed. Under the section, 3 it was expected to evaluate the level of influence of internal factors. Here, respondents were required to make a choice from the internal environmental elements listed. To measure selected independent variables, it was designed with a 5-point Likert scale (where $1=$ strongly disagree, and $5=$ strongly agree) statements which were applicable for all these 83 statements. Negative question reverses the same scale. Descriptive statistics that include frequencies and percentages will be used for the analysis of the data.

Reliability statistics concept was used to check the reliability of data. Cronbach's alpha associated with these scales were in between .702 to 0.940 Therefore, those scales show adequate internal consistency reliability.

\begin{tabular}{|l|c|}
\hline \multicolumn{1}{|c|}{ Variables } & $\begin{array}{l}\text { Reliability } \\
\text { (Cronbach's } \\
\text { Alpha) }\end{array}$ \\
\hline Management Expectations & .708 \\
\hline Organizational Dynamic Capabilities & .754 \\
\hline Organization's Structure & .825 \\
\hline Management Commitment and Corporate Culture & .702 \\
\hline CEO's Socio-Demographic characteristics. & .810 \\
\hline The level of Adoption of HRIS Application & .940 \\
\hline
\end{tabular}

Source: Survey Data, 2018

Table 1: Reliability analysis

\section{Findings}

The sample of the study was 120, Sri Lankan organizations which are located in western province. Although 96 responses were received, 3 of these were rejected due to errors. Therefore, the final sample size is 93 HR professionals. The total sample was categorized into three groups based on the level of adoption of HRIS application such as fully adopters, partly adopters, non-adopters. The highest percentage 70\% contain the partly adopters of total sample and only $30 \%$ of organizations were fully adopters in the sample. $17.5 \%$ respondents were in "less than one year used" category while the category of "Used 1-4 years" represents the $42.5 \%$ organizations in the sample. The category of "5-9 years" indicates $17.5 \%$ of organizations while the category "more than 9 years" indicates $22.5 \%$ of organizations in sample. Pearson's Correlation analysis was carried out as identify the relationship between variables of internal environmental factors and adoption of HRIS. 


\begin{tabular}{|l|l|l|l|l|l|}
\hline \multicolumn{1}{|c|}{ Variable } & Coefficient & $\begin{array}{c}\text { p- } \\
\text { Value }\end{array}$ & \multicolumn{1}{|c|}{ N } & \multicolumn{1}{|c|}{ Relationship } & Decision \\
\hline All internal factors & .456 & .005 & 90 & Significant weak positive & Accepted \\
\hline Management Expectations & .562 & .001 & 92 & Significant moderate positive & Accepted \\
\hline $\begin{array}{l}\text { Organizational Dynamic } \\
\text { Capabilities }\end{array}$ & .643 & .000 & 93 & Significant moderate positive & Accepted \\
\hline Organization's Structure & .356 & .005 & 93 & Significant weak positive & Accepted \\
\hline $\begin{array}{l}\text { Management Commitment and } \\
\text { Corporate Culture }\end{array}$ & .420 & .005 & .92 & Significant weak positive & Accepted \\
\hline $\begin{array}{l}\text { CEO's Socio -Demographic } \\
\text { characteristics. }\end{array}$ & .524 & .001 & 90 & Significant moderate positive & Accepted \\
\hline
\end{tabular}

**. Correlation is significant at the 0.01 level (2-tailed).

Source: Survey Data, 2018

Table 2: Summarized results on hypothesis testing

According to Table 2, there is a significant positive relationship between internal environmental factors and adoption of HRIS in Sri Lankan organizations.

\section{Conclusion}

The research findings confirm that only $30 \%$ of Sri Lankan organizations have fully adapted to the HRIS application while $70 \%$ of organizations were partially adopted. $42.5 \%$ of the respondent companies have had it for $1-4$ years while only $22.5 \%$ have had it for more than 9 years. Research problem of the study is whether internal environmental factors affect to the level of adoption of HRIS allocations in Sri Lankan organizations. Thus the research findings appear to agree with the findings of [5]. Study confirmed significant positive relationship between the internal environment factors and level of adoption of HRIS applications and reconfirmed the research findings of [2].

Under this study, it was tested the relationship between five internal environment factors and organizational adoption of HRIS separately. In addition to that, it was tested relationship between internal environment and organizational adoption of HRIS. Findings state that there is a significant positive relationship between each independent variable and the adoption of HRIS in Sri Lankan context. However, $r$ value is in between .350 to .643 . The highest $r$ value was recorded with organizational dynamic capabilities and the lowest value was recorded with organizational structure (.356). In other words it was recorded a weak positive relationship between organizational structure and HRIS adoption. In addition to that, management expectations (.562), management commitment and corporate culture (.420) and CEO's socio -demographic characteristics (.524) recorded moderate level relationship with HRIS adoption. However, organizational dynamic capabilities (.643) was recored strong relationship with HRIS adoption. Whem all indipendnent variables takes together, it was confirm moderate level relationship with HRIS adoption. It is further confirmed the research findings of previous researchers [11]; [6]. In 2018, [13] conducted a study to test the same relationships in the manufacturing sector and confirm the moderate level relationship between organizational structure and adoption of HRIS. However, this study just confirms a significant weak relationship.

The study found, the moderate level relationship between management expectations and adoption of HRIS. It is reconfirmed the findings of [26]; [14]. [2]; [25], 1999 confirm a positive relationship between organizational dynamic capabilities and adoption of HRIS. Those are reconfirming by these study findings. CEO's socio-demographic characteristics) [2]; [4]; [25] recognized the importance of CEO's socio-demographic characteristics for the successful adoption of HRIS. This study again reconfirms this past findings. The findings of the study revealed that the general HRIS application has spread in the context but remains on an administrative level. A mainly administrative task like record keeping is supported while advanced strategic or decision support oriented applications are lacking.

\section{Limitations of the study}

The researcher identified several limitations of the study. The first limitation identified is the sample as the sample is selected only from western province in Sri Lanka. Moreover, the research study sources of influential factors were limited only to 5 dimensions and there can be other internal factors that can be influenced. In addition to that, it was not teasted external factors that can influence to the adoption of HRIS.

\section{Recommendations for future research}

The sample was only 93 HR managers and the same research can be carried out by using a much larger sample. Further, the research methodology can be designed in order to identify more internal influential factors as well as external factors apart from the factors which were taken into consideration by the present study. When a research take employees from different industries and sectors comparative analysis can be carried out. 


\section{References}

[1.] AL-Dmour R H and Al-Zu'bi Z (2014), "Factors Inhabiting and Motivating the Adoption of HRIS in Business Organization,” International Business Research, Vol. 7, p139,2014.

[2.] Al-Dmour R H, (2014), An Integration Model for Identifying the Determinants of the Adoption and Implementation Level of HRIS Applications and Its Effectiveness in Business Organisations in Jordan, A Thesis Submitted for the Degree of Doctor of Philosophy, School of Information Systems, Computing and Mathematics, Brunel University London

[3.] Badhurudheen A S (2018), The Impact of Internal Environmental Factors on The Level of Adoption of Human Resource Information System: The Case of Manufacturing Companies in Western Province of Sri Lanka, Journal of Information Systems \& Information Technology (JISIT), Vol. 2 No. 2, ISSN: 2478-0677

[4.] Bassellier, G., Benbasat, I. and Reich, B.H. (2003) "The influence of business managers' IT competence on championing IT", Information Systems Research, vol. 14, no. 4, pp. 317-336.

[5.] De Alwis, A. C. (2010). The Impact Of Electronic Human Resource Management On The Role Of Human Resource Managers. Ekonomika A Management, 1-14.

[6.] Eder, L.B. and Igbaria, M. (2001) "Determinants of intranet diffusion and infusion", Omega, vol. 29, no. 3, pp. 233 242.

[7.] Fink, D. (1998) "Guidelines for the successful adoption of information technology in small and medium enterprises", International Journal of Information Management, vol. 18, no. 4, pp. 243-253.

[8.] Galhena, B. L. (2015). Behavior of e-HRM Adoption: Empirical Evidence form Organizations in Developing Context.

[9.] Hussain, Z., Wallace, J. and Cornelius, N.E. (2007) "The use and impact of human resource information systems on human resource management professionals", Information \& Management, vol. 44, no. 1, pp. 74-89.

[10.] Jenkins, M.L. and Lloyd, G. (1985) "How corporate philosophy and strategy shape the use of HR information systems", Personnel, vol. 62, no. 5, pp. 28-38.

[11.] Lai, V.S. and Guynes, J.L. (1997) "An assessment of the influence of organisational characteristics on information technology adoption decision: a discriminative approach", Engineering Management, IEEE Transactions on, vol. 44, no. 2, pp. 146-157.

[12.] Lin C.Y.Y. (1997) "Human resource information systems: Implementation in Taiwan", Research and Practice in Human Resource Management, vol. 5, no. 1, pp. 57-72.in,

[13.] Madushani M K (2016) The relationship beween internal environmental factors and level of adoption of HRIS applications in Manufacuring sector in Colombo District, Sri Lanka, 3rd HRM Student Research Symposium , Univeraity of Kelaniya

[14.] Masum, H., Rao, A., Good, B.M., Todd, M.H., Edwards, A.M., Chan, L., Bunin, B.A., Su, A.I., Thomas, Z. and Bourne, P.E. (2013) "Ten Simple Rules for Cultivating Open Science and Collaborative R\&D", PLoS computational biology, vol. 9, no. 9 .

[15.] Mathieson, K. (1991) "Predicting user intentions: comparing the technology acceptance model with the theory of planned behavior", Information systems research, vol. 2, no. 3, pp. 173-191.

[16.] Mikulic, I[va] \& Stefanic, A[nja] (2018). The Adoption of Modern Technology Specific to Industry 4.0 by Human Factor, Proceedings of the 29th DAAAM International Symposium, pp.0941-0946, B. Katalinic (Ed.), Published by DAAAM International, ISBN 978-3-902734-20-4, ISSN 1726-9679, Vienna, Austria DOI: 10.2507/29th.daaam.proceedings. 135

[17.] Nadeeshani P K M N and De Alwis A c (2016) Relationship between Enviornmental Factors and Adoption of HRIS in Service Organizations , , 3rd HRM Student Research Symposium , Univeraity of Kelaniya

[18.] Nagasinghe C M and De Alwis A.C. (2016), the impact of implimantation of level of HRIS applications on organizational effectiveness . A study of apparel sector organizations in western province in Sri Lanka, 3rd HRM Student Research Symposium , Univeraity of Kelaniya

[19.] Ruël, H., Bondarouk, T. and Looise, J.K. (2004) "e-HRM: innovation or irritation: an explorative empirical study in five large companies on web-based HRM", Management Revue, vol. 15, no. 3, pp. 364-380.

[20.] Stoneman, P.L. and David, P.A. (1986) "Adoption subsidies vs information provision as instruments of technology policy", The Economic Journal, vol. 96, pp. 142-150.

[21.] Tannenbaum, S.I. (1990) "Human resource information systems: User group implications", Journal of Systems management, vol. 41, no. 1.

[22.] Tannennbaum, S. I. (1990). HRIS: User Group Implications. Journal of System management, 41(1), 27-32.

[23.] Teece D G, Pisano G, and Shuen A (1997) Dynamic Capabilities and Strategic management, Strategic Management Journal. 18, pp $509-533$

[24.] Teo, T.S.H., Soon, L.G. and Fedric, S.A. (2001) "Adoption and impact of human resource information systems (HRIS)", Research and Practice in Human Resource Management, vol. 9, no. 1, pp. 101-117.

[25.] Thong, J.Y. (1999) "An integrated model of information systems adoption in small businesses", Journal of Management Information Systems, vol. 15, no. 4, pp. 187-214.

[26.] Troshani, I., Jerram, C. and Hill, S.R. (2011) "Exploring the public sector adoption of HRIS", Industrial Management \& Data Systems, vol. 111, no. 3, pp. 470-488 